\title{
Article \\ Plant-Derived Smoke Ameliorates Salt Stress in Wheat by Enhancing Expressions of Stress-Responsive Genes and Antioxidant Enzymatic Activity
}

\author{
Nailla Hayat ${ }^{1}$, Neelum Afroz ${ }^{1,2}$, Shafiq Rehman ${ }^{3}$, Syeda Huma Bukhari ${ }^{1}$, Khalid Iqbal ${ }^{1}$, Amana Khatoon ${ }^{1}$, \\ Nadia Taimur ${ }^{1}$, Shazia Sakhi ${ }^{2} \mathbb{D}$, Nisar Ahmad ${ }^{2} \mathbb{D}$, Riaz Ullah ${ }^{4} * \mathbb{D}$, Essam A. Ali ${ }^{5}$, Ahmed Bari ${ }^{5}$, \\ Hidayat Hussain ${ }^{6}$ (D) and Ghazala Nawaz ${ }^{1, *}$
}

1 Department of Botany, Kohat University of Science and Technology, Kohat 26000, Pakistan; nailahayatktk@gmail.com (N.H.); afrozneelamktk@gmail.com (N.A.); huma@kust.edu.pk (S.H.B.); khalidiqbalkhan5560@gmail.com (K.I.); proteomics.sp@gmail.com (A.K.); nadiataimur21@gmail.com (N.T.)

2 Center for Biotechnology and Microbiology (CB\&M), Center of Plant Sciences and Biodiversity, University of Swat, Mingora 19200, Pakistan; shaziasakhi@hotmail.com (S.S.); ahmadn@uswat.edu.pk (N.A.)

3 Department of Biology, University of Haripur, Haripur 22620, Pakistan; drshafiq@uoh.edu.pk

4 Department of Pharmacognosy, College of Pharmacy, King Saud University, Riyadh 11451, Saudi Arabia

5 Department of Pharmaceutical Chemistry, College of Pharmacy, King Saud University, Riyadh 11451, Saudi Arabia; esali@ksu.edu.sa (E.A.A.); abari@ksu.edu.sa (A.B.)

6 Department of Bioorganic Chemistry, Leibniz Institute of Plant Biochemistry, Weinberg 3, D-06120 Halle (Salle), Germany; Hidayat.Hussain@ipb-halle.de

* Correspondence: rullah@ksu.edu.sa (R.U.); Ghazala.nawaz@kust.edu.pk (G.N.)

Citation: Hayat, N.; Afroz, N.; Rehman, S.; Bukhari, S.H.; Iqbal, K.; Khatoon, A.; Taimur, N.; Sakhi, S.; Ahmad, N.; Ullah, R.; et al. Plant-Derived Smoke Ameliorates Salt Stress in Wheat by Enhancing Expressions of Stress-Responsive Genes and Antioxidant Enzymatic Activity. Agronomy 2022, 12, 28. https://doi.org/10.3390/ agronomy12010028

Academic Editor: Bu-Jun Shi

Received: 7 November 2021

Accepted: 17 December 2021

Published: 24 December 2021

Publisher's Note: MDPI stays neutral with regard to jurisdictional claims in published maps and institutional affiliations.

Copyright: (C) 2021 by the authors. Licensee MDPI, Basel, Switzerland. This article is an open access article distributed under the terms and conditions of the Creative Commons Attribution (CC BY) license (https:// creativecommons.org/licenses/by/ $4.0 /)$.

\begin{abstract}
Abiotic stresses are the biggest threat to the increasing population worldwide. Salt stress is one of the most significant abiotic stresses, affecting $20 \%$ of the crop production around the world. Plant-derived smoke (PDS) has been reported as a biologically active plant product in stimulating seed germination, seedling growth and physiological characteristics of crops under abiotic stress conditions. Nevertheless, studies showing how PDS alleviates salt stress are largely unknown. Here, we report the molecular mechanism of how PDS could alleviate salt stress in wheat. Initially, PDS at 2000 ppm enhanced seed germination, root/shoot length and seedling fresh weight. However, PDS at 1000 and 500 ppm did not show any significant effect. Salt stress at 150 and $200 \mathrm{mM}$ significantly reduced seed germination rate, root/shoot length and fresh weight of the wheat seedlings. Interestingly, PDS supplementation at $2000 \mathrm{ppm}$ concentration was sufficient to restore seed germination under salt stress condition. Moreover, PDS improved root/shoot length and seedling biomass under 150 and $200 \mathrm{mM}$ salt stress, suggesting that PDS is a potent plant product, capable of abiotic stress alleviation in crops. In comparison to the control, PDS-treated seedlings displayed increased activity of major antioxidative enzymes such as superoxide dismutase, peroxidase and ascorbate peroxidase under salt stress, resulting in reduced levels of hydrogen peroxide and lipid peroxidase, showing that PDS can possibly help in salt stress amelioration by regulating redox homeostasis. Importantly, salt stress altered the expression of germination marker genes, such as TaSAM, TaPHY, TaBGU (germination positive effectors), TaLEA and TaGARS34 (germination negative effectors), suggesting the potential role of PDS in the germination pathway under salt stress. Further, PDS modulated the transcript levels of several salt stress stress-responsive genes, including TaSOS4, TaBADH and TaHKT2. In conclusion, this study provides a molecular and physiological basis for elucidating the mechanism of how PDS functions in stress induction in wheat, as well as demonstrates the importance of PDS in agricultural practices, laying the groundwork for future research into the role of PDS in the amelioration of abiotic stresses in various plants.
\end{abstract}

Keywords: smoke; salt stress; stress alleviation; germination marker genes; salt marker genes 


\section{Introduction}

Abiotic stresses, such as salt, cold, drought, UV and severe temperature, are the key causes of reduction of plant yield and productivity worldwide [1]. Stresses influence physiology, morphology, and molecular characteristics of plants [2]. Salinity is the second biggest threat to the cultivated lands and has been reported to diminish $20 \%$ of crop yield worldwide [3,4]. Salinity stress has resulted in crop yield losses of approximately 8 million hectares of farmed land in most developing nations that lack an effective reclamation infrastructure [5]. Salt stress lowers germination and post-germination growth in various crop species such as rice cultivars, phaseolus species, maize, and tomato varieties [4,6-10]. Salt stress harms plant metabolism, e.g., over production of ROS (reactive oxygen species), which reduces the cellular carbohydrates, lipids, and proteins, and damages the DNA of plants [11,12], resulting in losses of 30\% of crop yield annually [3]. An excess of salt disrupts photosynthesis and pigments, resulting in reduced light absorption in plants [13]. Furthermore, less frequent stomatal opening and lower $\mathrm{CO}_{2}$ intake in leaves result in a decrease in the carbon fixation response under salt and drought stress [3,14]. Although plants adopt certain intrinsic mechanisms to withstand salinity stress, these mechanisms result in stunted growth and reduction in yield. To cope with the losses caused by stresses and satisfy the growing population's food demands, it is critical to identify cost-effective solutions to improve crops and enhance yields under abiotic stresses [15]. Overall, these studies indicate that identifying the stress-responsive compounds and genes implicated in cellular signaling is critical for improving crop yield.

Plant-derived smoke (PDS) is a fire product and has been significantly effective in enhancing plant growth and distribution [16]. PDS has been found crucial in various morphological and physiological processes such as seed germination of celery/maize and tomato, dormancy breakage in red rice seeds, and seedling growth and fresh biomass of okra, mung bean and tomato [17-19]. PDS affects physiological aspects of crops, such as increased total flavonoid content, stimulated total flavonoid content, increased secondary metabolites such as flavonoids and phenolics, increased calcium $\left(\mathrm{Ca}^{++}\right)$and potassium $\left(\mathrm{K}^{+}\right)$ ion levels, and reduced sodium $\left(\mathrm{Na}^{+}\right)$ion levels. It has also increased total nitrogen, total soluble protein, and antioxidant activities in tomato, banana, and aloe [20-22]. Recently, Amana et al., in a 2020 review, provided a detailed investigation on the role of PDS in morphological, physiological, and biochemical aspects of plants, revealing the diverse roles of PDS in plant growth and stress responses [23].

Reportedly, PDS has been found to play an important role in the amelioration of abiotic stresses. Seed priming in PDS has been shown to improve seed germination and seedling growth in salt-stressed maize [22,24]. Smoke-derived compounds, such as Karrikin, have shown amelioration of salt and osmotic stresses by increasing the germination and post-germination growth in Sapium sabiforum [25]. Karrikins have also increased seed germination and seedling growth in Eragrostis tef (zucc.) under heat and osmotic stress [26] by modulating GA biosynthesis-related genes, boosting ROS-scavenging antioxidant enzymes and sugar mobilization in seeds [27-29]. In Sapium sabiforum, seedling growth has been improved by Karrikins under salt stress with the stimulation of SOS1, WKKY33, DREB2 and EFR5 genes under salt stress [25].

Wheat (Triticum aestivum L.) is one of the world's most widely grown cereal crops, with $40 \%$ of the world's population relying on it to meet their nutritional needs [30]. By 2030 , it is expected that the global population will be increased by 8 billion people, making food availability a major issue [31]. It has been reported that abiotic stress challenges had a negative impact on wheat morphology, physiology, and biochemical characteristics [32].

Although much has been documented about the promoting effects of PDS in various crop species, its effects on wheat morphology and how it affects molecular and physiological mechanisms that regulate growth in wheat under salt stress are largely unknown. Therefore, we hypothesized that PDS can directly regulate wheat growth by scavenging ROS by improving the activity of the antioxidant enzymes and inducing expressions of stressresponsive genes in salt stress conditions. To validate our hypothesis, we employed PDS 
at various concentrations and discovered that salt stress at 150 and $200 \mathrm{mM}$ decreased germination and post-germination seedling growth in wheat, which was restored by PDS application. We measured shoot and root length and fresh weight under salt stress condition. We investigated the ROS, lipid peroxidase, and levels of antioxidative enzymes under salt stress. The results obtained confirmed our hypothesis. Further, we investigated the expression patterns of germination and salt-stress-responsive genes in wheat. Our research demonstrates the physiological and molecular processes of PDS in the induction of salt stress tolerance in wheat. It also describes that PDS could have a high potential utility in agricultural practices.

\section{Results}

\subsection{Plant-Derived Smoke Solution Enhances Seed Germination under Normal and Salt Stress Condition}

Seeds treated with PDS 2000 ppm showed 60\% germination at day 1 and 96\% at day 2 . On the other hand, seeds treated with distilled water (control) showed $46 \%$ germination at day 1 and $63 \%$ at day 2, which indicates that PDS significantly increases seed germination in wheat (Figure 1A). PDS at 1000 ppm and 500 ppm did not show any significant difference as compared to control in the germination rate. (Supplementary Figure S1A). Salt stress at 150 and $200 \mathrm{mM}$ reduced and delayed seed germination by $13 \%$ at day 1, and 36\% at day 2. The maximum germination with salt stress was achieved at day 7 , which was late as compared to PDS and control. A severe reduction in germination rate was observed under salt $200 \mathrm{mM}$ concentration, which was $0.33 \%$ on day 1 and $23 \%$ on day 2 . Maximum $50 \%$ germination was achieved on day 7. Since PDS at 2000 ppm enhanced seed germination, we wanted to evaluate whether PDS at $2000 \mathrm{ppm}$ can alleviate the inhibitory effects of salt stress. The results showed that PDS 2000 ppm enhanced seed germination by 33\% and $23 \%$ after $24 \mathrm{~h}$ under $150 \mathrm{mM}$ and $200 \mathrm{mM}$ salt stress, compared to 13 and $0.33 \%$ on the initial two days, respectively. These results indicate that plant-derived smoke solution at 2000 ppm has promoting effects on seed germination (Figure 1B); particularly, it has salt stress alleviating capability. Our findings also show that the effect of PDS on wheat seed germination is concentration dependent.

\section{A}

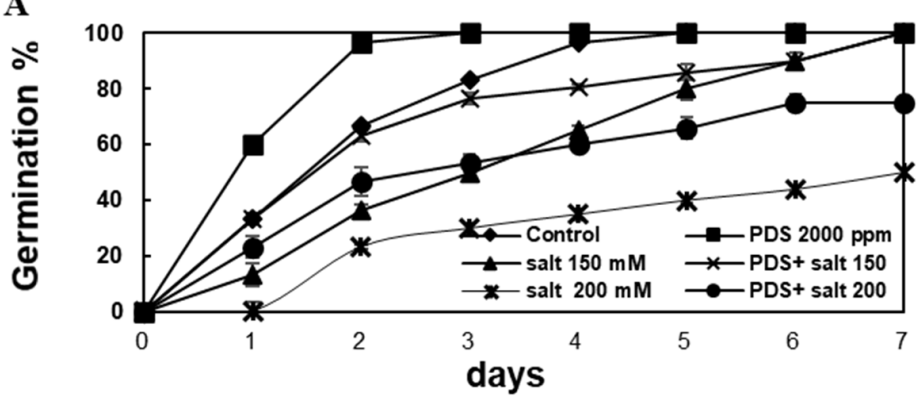

B

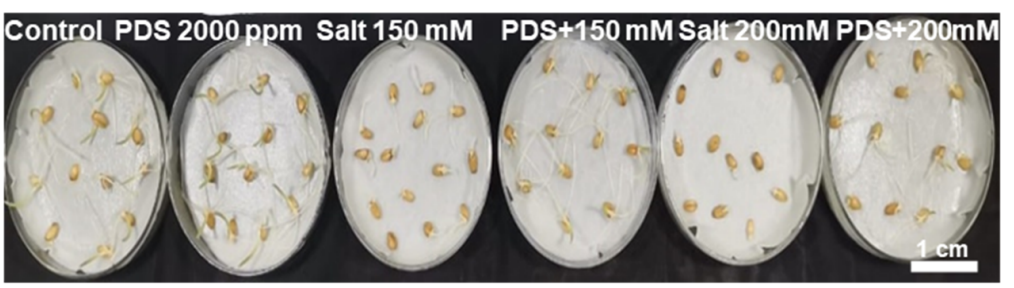

Figure 1. Effect of PDS on germination rate of wheat under normal and salt stress conditions. (A) Wheat seeds were subjected to PDS 2000 ppm, salt 150 and $200 \mathrm{mM}$ and PDS + salt treatments $(150+2000$ ppm and $200+2000$ ppm). Germination rate was observed at day 1-7. PDS 2000 ppm accelerated germination rate and alleviated the salt stress (150 and $200 \mathrm{mM}$ ) (Figure 1A). X-axes represent number of days. (B) Photographs were taken at day $2(48 \mathrm{~h})$. All data were analyzed using one-way ANOVA, with multiple comparisons using LSD test at a significance threshold of $p \leq 0.05$ $(n=10)$. Each independent experiment was repeated three times. 


\subsection{Plant-Derived Smoke Solution Modulates Expression of Germination Marker Genes under Salt Stress}

To elucidate how PDS (2000 ppm) enhances wheat seed germination and alleviates salt stress, we analyzed the expression patterns of several germination marker genes, including germination enhancers or positive effectors and germination inhibitors or negative effectors. Germination positive effectors included Isocitrate lyase (ISO), S-adenosylmethionine synthetase $(S A M)$, Phytochrome genes (PHY), $\beta$-glucosidase $(B G U)$, and negative effectors included Late embryogenesis abundant (TaLEA), and Gibberellic acid-stimulated regulator (TaGASR34). The results indicated an approximate 4-fold increase in TaSAM expression and 2.5-fold in TaBGU expression levels under PDS $2000 \mathrm{ppm}$. Salt stress $(150 \mathrm{mM} \mathrm{NaCl})$ reduced the expressions of TaSAM (0.5-fold) and TaBGU (0.1-fold), which were restored to 3- and 2 -fold, respectively, by the application of PDS $2000 \mathrm{ppm}$. On the other hand, expressions of TaGARS34 and TaLEA (germination negative regulators) were significantly increased under salt stress (Figure 2E,F) while their expressions were reduced by PDS 2000 ppm. Application of PDS $2000 \mathrm{ppm}+$ salt $150 \mathrm{mM}$ decreased the expression levels of TaLEA and TaGASR34. These results indicate that PDS decreases the expressions of germination negative regulators under salt stress. Further, these findings show that PDS can alleviate salt stress at the germination level by modulating expression patterns of the germination marker genes. However, the mechanism of how plant-derived smoke affects expression levels of germination marker genes still needs to be discovered.

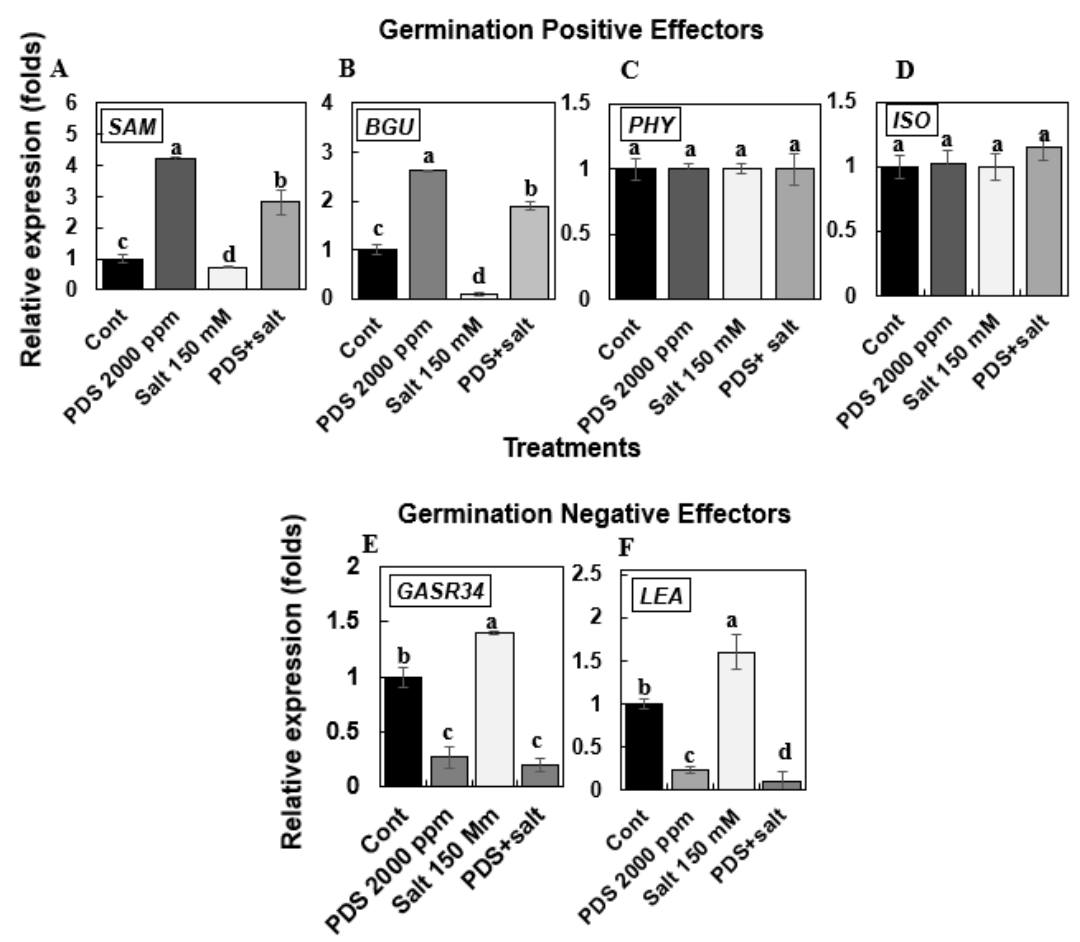

Figure 2. Expression patterns of germination marker genes were analyzed under PDS 2000 ppm and salt (150 and $200 \mathrm{mM}$ ). Wheat seeds were germinated in Petri plates supplemented with PDS $2000 \mathrm{ppm}$. Germinated seeds after $48 \mathrm{~h}$ were collected for extraction of total RNA to perform qRTPCR. (A-D) The bars show the fold increase or decrease in the expression levels of germination positive effector genes upon treatment with PDS 2000 ppm, salt stress, salt + PDS. (E,F) Graphical bars represent the effect of PDS 2000 ppm, salt stress $(150 \mathrm{mM})$ and salt + PDS 2000 ppm on the expression levels of germination negative marker genes in wheat. The $y$-axis shows fold change in the expression of genes. The $x$-axis represents the different treatments. All data were analyzed using one-way ANOVA, with multiple comparisons using LSD test at a significance threshold of $p \leq 0.05$. Three independent experiments were performed to obtain mean values and standard error bars for each germination experiment. The different lowercase alphabets represent homogeneous subsets and it's indicates the statistical significantly according to Fisher LSD at level $p<0.05$. 


\subsection{Application of PDS Improves Wheat Plantlets Growth and Fresh Weight under Salt Stress}

Next, to measure the effect of PDS on wheat seedling growth and whether it can alleviate salt stress, we used various PDS concentrations, i.e., 500, 1000 and 2000 ppm, and determined the effect of PDS on shoot and root length. The data indicated that PDS 2000 ppm increased roots up to $16 \mathrm{~cm}$ as compared to control, which was noted as $13 \mathrm{~cm}$ (Figure 3A). Salt at $150 \mathrm{mM}$ caused a significant reduction in root $(6 \mathrm{~cm})$ length, whereas the effect of salt at $200 \mathrm{mM}$ concentration was more severe on root length and showed approximately $3 \mathrm{~cm}$ length. Application of PDS $2000 \mathrm{ppm}+$ salt (150 mM and $200 \mathrm{mM})$ on roots significantly increased root length to 11 and $9 \mathrm{~cm}$, respectively (Figure 3A). The shoot length measured under PDS 2000 ppm was $14 \mathrm{~cm}$ whereas under control conditions (distilled water treatment) it was noted to be $12 \mathrm{~cm}$, indicating that plant-derived smoke solution has a promoting effect on shoot length. The shoot length observed under salt treatment at 150 and $200 \mathrm{mM}$ was approximately 7 and $4 \mathrm{~cm}$, respectively. However, combined application of PDS 2000 ppm + 150 and 200 mM enhanced shoot length by 11 and $8 \mathrm{~cm}$, respectively (Figure $3 \mathrm{~B}$ ). These results indicate that PDS has the capability of increasing root and shoot length and has the potential to mitigate salt stress in wheat. PDS at 1000 ppm slightly promoted shoot and root length. However, PDS 500 ppm did not show any significant change in seedling growth (Supplementary Figure S1B). These results show that PDS effects vary at various concentrations.
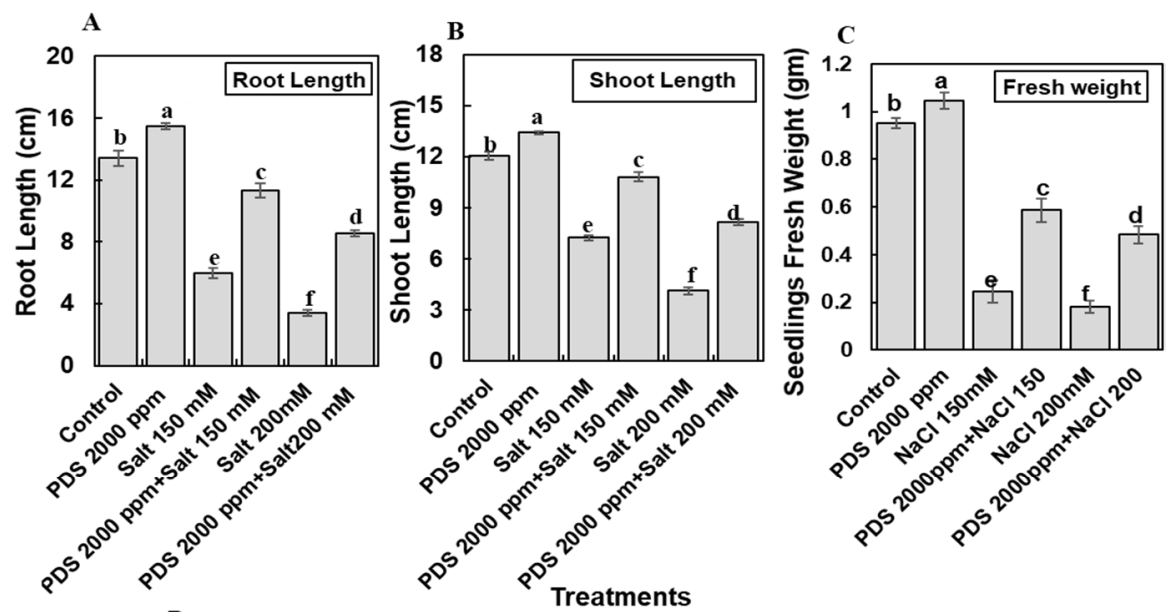

D

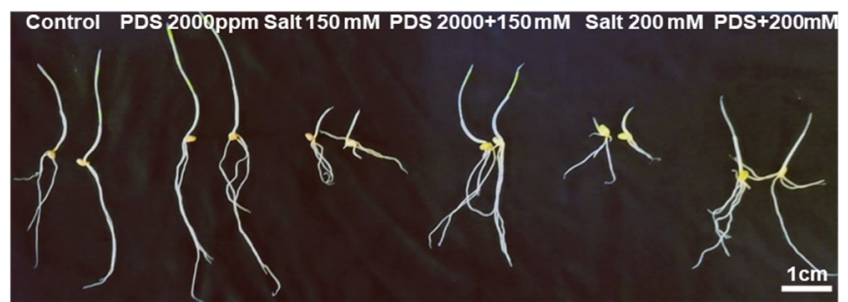

Figure 3. Effect of PDS on root and shoot length of wheat under normal and salt stress. Seedling growth was observed under control, PDS 2000 ppm, salt $150 \mathrm{mM}$ and $200 \mathrm{mM}$, and PDS 2000 ppm + salt 150 or $200 \mathrm{mM}$ treatment. (A) Length of root was observed at day 7 after protruding of the radical. Root length was measured by randomly selecting 10 plants from each treatment. The $x$-axis represents different treatments. (B) Shoot length was measured at day 7 by randomly selecting 10 seedlings from each treatment. (C) Fresh weight was quantified when the morphological changes were clearly visible (day 7), the fresh weight (g) of the 10 plants from each treatment was assessed. Three different batches of trials yielded the mean values and standard error (bars on graph). (D) Photographs were taken at day 7. White line represents the scale bar $(1 \mathrm{~cm})$. All data were analyzed using one-way ANOVA, with multiple comparisons using LSD test at a significance threshold of $p \leq 0.05(n=10)$. The different lowercase alphabets represent homogeneous subsets and it's indicates the statistical significantly according to Fisher LSD at level $p<0.05$. 
Moreover, application of PDS at 2000 ppm increased seedling fresh weight as compared to control. In a similar way, PDS 2000 ppm alleviated salt stress and the fresh weight (g) of seedlings was found to be more than salt-stress-treated seedlings (Figure 3C).

These findings show that PDS 2000 ppm has promoting effects on wheat seedlings (Figure 3D) and has the capability of alleviating salt stress.

\subsection{Plant-Derived Smoke Solution Modulates Expression of Salt Stress Marker Genes}

To elucidate how PDS 2000 ppm promotes root and shoot length under salt stress, we analyzed the expression patterns of some salt stress marker genes including SOS1 (salt overly sensitive 1), P5CS (Pyrroline-5- carboxylate synthetase), SOS4 (Salt overly sensitive 4), HKT2 (Cation transporter) and BADH (Betaine-aldehyde dehydrogenase). The results showed that application of PDS 2000 ppm induced expression of SOS4 (2-fold), P3CS (1.5-fold) and HKT2 (1.5-fold) as compared to control (Figure 4A-E). We also analyzed the expression patterns of the salt marker genes under $150 \mathrm{mM}$ salt stress and obtained reduced levels of SOS1, SOS4 and P3CS as compared to control and PDS (Figure 4A,B,D). Supplementation of PDS $2000 \mathrm{ppm}$ to salt $150 \mathrm{mM}$ alleviated salt stress and increased the expressions of SOS4 up to 2.1-fold, HKT2 and BADH up to 1.5-fold and P3CS up to 1.4-fold. It can be deduced that PDS at 2000 ppm dilution actively targets the salt-stress-related genes in the induction of stress adaptation in wheat (Figure 4A-E). However, how PDS induces expression of salt stress marker genes under salt stress needs to be investigated.

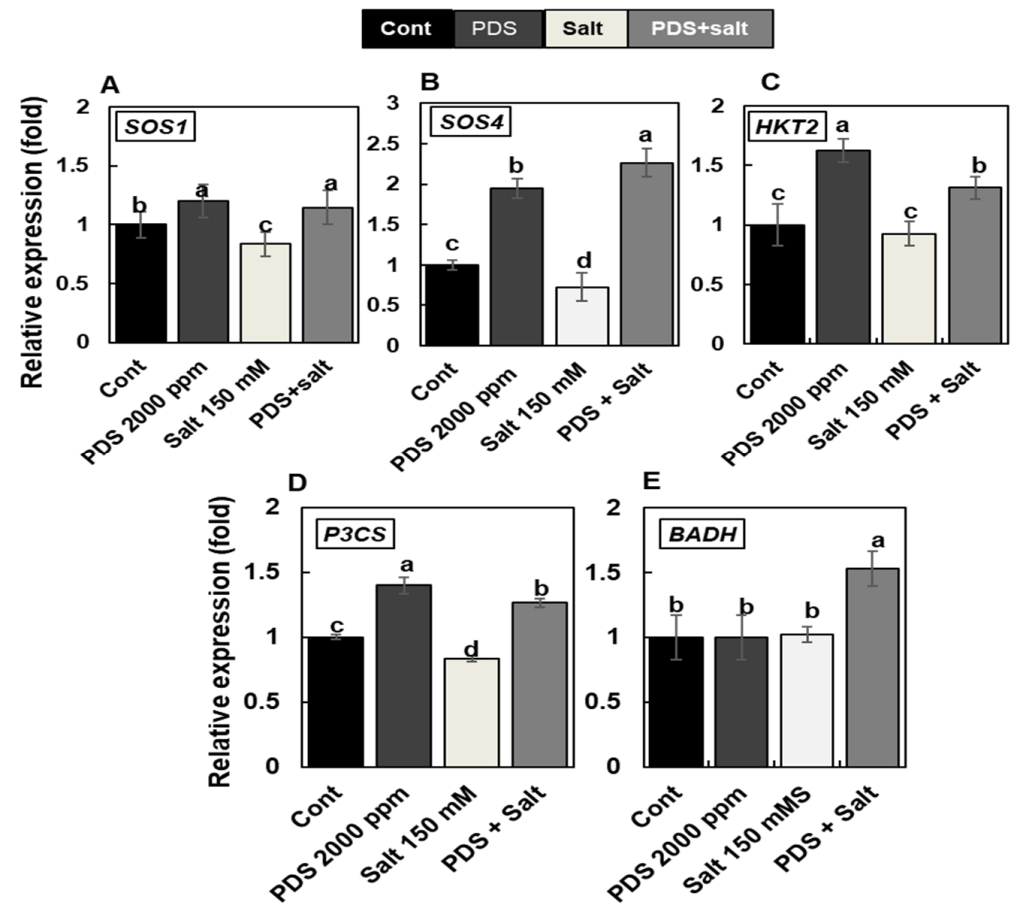

Figure 4. Expression patterns of the salt-responsive genes measured by qRT-PCR. Wheat seeds were sown in Petri plates. Seeds were treated with distilled water (control), PDS 2000 ppm, salt 150 mM, and PDS 2000 ppm + salt $150 \mathrm{mM}$. Germinated seeds were collected for total RNA extraction to perform qRT-PCR. The histogram bars show the fold increase or decrease in the expression level of gene. (A) Represents the fold change in the expression of SOS1 gene. (B) Represents the expression patterns of SOS4. (C) HKT2. (D) P3CS. (E) BADH. The $x$-axis shows the type of treatment and $y$-axis represents the change in relative expression folds of salt stress marker genes. Each gene data were analyzed by one-way ANOVA followed by LSD test for multiple comparison and represented by letters on the bars $(p \leq 0.05)$. Three independent experiments were performed to obtain the mean values and standard error bars for each germination experiment. The different lowercase alphabets represent homogeneous subsets and it's indicates the statistical significantly according to Fisher LSD at level $p<0.05$. 


\subsection{Plant-Derived Smoke Solution Reduces Oxidative Stress $\left(\mathrm{H}_{2} \mathrm{O}_{2}\right)$ and Lipid Peroxidation}

To determine the effect of PDS on reactive oxygen species (ROS) under normal and salt stress conditions, we analyzed levels of the $\mathrm{H}_{2} \mathrm{O}_{2}$ (hydrogen peroxide) as a representative of ROS in wheat seedlings. Application of PDS 2000 ppm reduced the levels of $\mathrm{H}_{2} \mathrm{O}_{2}$ whereas PDS at 1000 and $500 \mathrm{ppm}$ did not significantly affect levels of the $\mathrm{H}_{2} \mathrm{O}_{2}$ (Figure 5A). Upon application of salt at 150 and $200 \mathrm{mM}$ concentrations the level of $\mathrm{H}_{2} \mathrm{O}_{2}$ was observed to be 2.592 and $2.965 \mu \mathrm{M} \mathrm{g} / \mathrm{FW}$ respectively (Figure $5 \mathrm{~B}$ ). Under control conditions the $\mathrm{H}_{2} \mathrm{O}_{2}$ level was $1.5 \mu \mathrm{M}$ g/FW. These results indicate an increase in oxidative stress in salt-treated wheat seedlings. To know whether PDS $2000 \mathrm{ppm}$ has the capability to reduce levels of $\mathrm{H}_{2} \mathrm{O}_{2}$ under salt stress conditions, salt solutions, i.e., $150 \mathrm{mM}$ and $200 \mathrm{mM}$, were supplemented with PDS 2000 ppm and their effect was analyzed on $\mathrm{H}_{2} \mathrm{O}_{2}$. The results showed significant decrease in $\mathrm{H}_{2} \mathrm{O}_{2}$ levels to 1.6 and $2.1 \mu \mathrm{Mg} / \mathrm{FW}$, respectively. These results conclude that PDS is potent in reducing $\mathrm{H}_{2} \mathrm{O}_{2}$ in wheat under salt stress (Figure 5A,B). Lipid peroxidase activity in the cell is used as a biochemical marker to measure the cell membrane injury [33]. Thiobarbituric acid reactive substance (TBARS) is a by-product of lipid peroxidation and measures the malondialdehyde (MDA), which is the end product formed as a result of decomposition of lipid peroxidation products [33]. The level of TBARS was found decreased in seedlings treated with PDS 2000 ppm as compared to control. On the other hand, application of salt at 150 or $200 \mathrm{mM}$ increased the TBARS level in cells, indicating that cellular membrane injury was caused as result of salt stress (Figure 5C). Interestingly, the addition of PDS $2000 \mathrm{ppm}$ in 150 and $200 \mathrm{mM}$ salt solutions significantly lowered the TBARS levels. These results show that PDS has the capability to recover cellular membrane injury caused by salt stress.

A

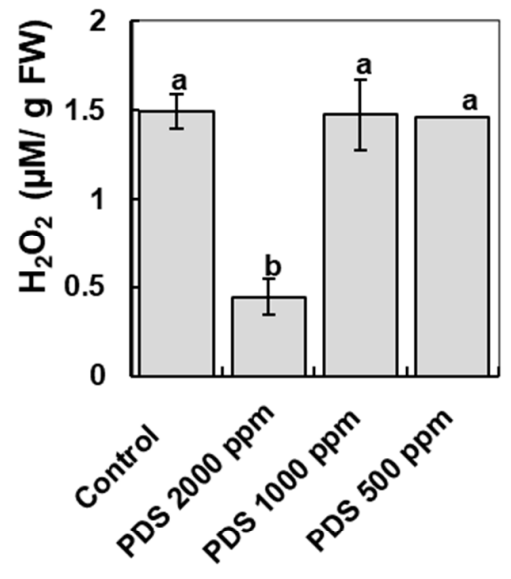

B

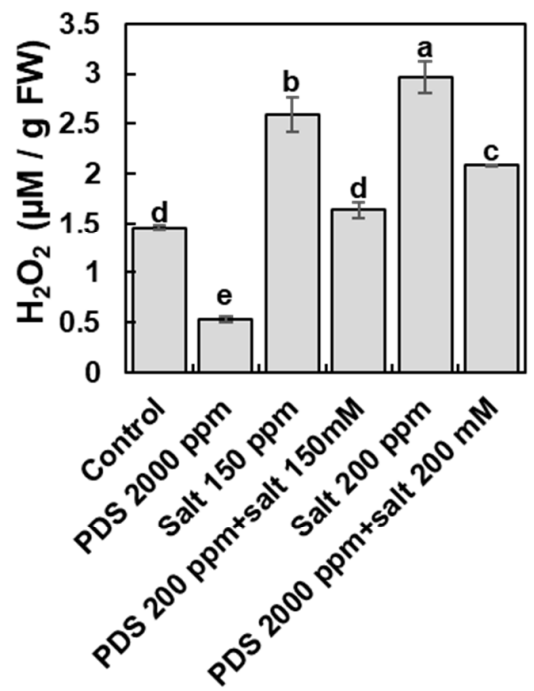

C

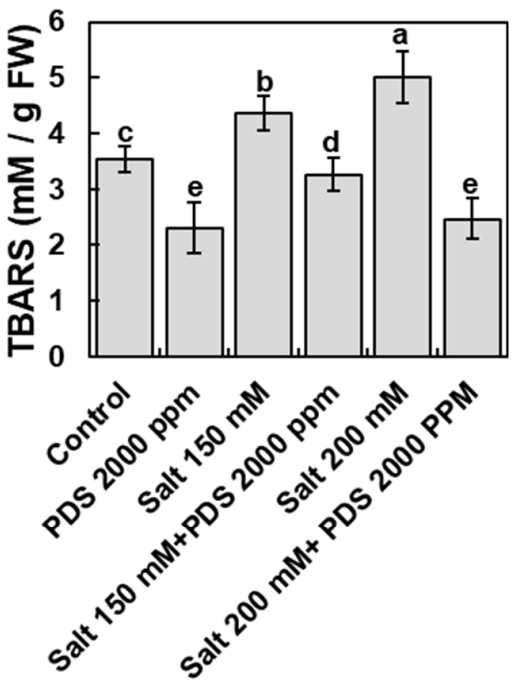

Treatments

Figure 5. Effect of PDS on reactive oxygen species (ROS) $\left(\mathrm{H}_{2} \mathrm{O}_{2}\right)$ under normal and salt stress. (A) The level of $\mathrm{H}_{2} \mathrm{O}_{2}$ was determined under PDS (2000, 1000, and 500 ppm). (B) Salt (150 and $\left.200 \mathrm{mM}\right)$, and salt supplemented with PDS 2000 ppm. Seven-day-old seedlings were harvested and subjected for the analysis of $\mathrm{H}_{2} \mathrm{O}_{2}$. Five seedlings were randomly selected from each treatment and $\mathrm{H}_{2} \mathrm{O}_{2}$ was assessed. (C) Lipid peroxidation was analyzed in terms of TBARS using 7-day-old seedlings. Five seedlings were randomly collected from each treatment and TBARS was measured. Data are means \pm SE obtained from three different batches of replicates. All data were analyzed using one-way ANOVA, with multiple comparisons using LSD test at a significance threshold of $p \leq 0.05(n=5)$. The different lowercase alphabets represent homogeneous subsets and it's indicates the statistical significantly according to Fisher LSD at level $p<0.05$. 


\subsection{Plant-Derived Smoke Solution Reduces Oxidative Stress by Enhancing Levels of Antioxidative Enzymes}

The superoxide dismutase activity (SOD) of the wheat plants was assessed under various treatments, including PDS 2000 ppm, salt 150 and $200 \mathrm{mM}$, and salt supplemented with PDS $2000 \mathrm{ppm}$. The results showed a significant change in the activity of SOD under PDS $2000 \mathrm{ppm}$ as compared to control plants, whereas application of salt 150 and $200 \mathrm{mM}$ indicated a decline in SOD activity to 0.2 and $0.1 \mu \mathrm{M} / \mathrm{g} \mathrm{FW}$, respectively, as compared to control and PDS treatments (Figure 6A). Supplementation of 150 and $200 \mathrm{mM}$ salt solutions with PDS $2000 \mathrm{ppm}$ increased the activity of SOD by 0.33 and $0.45 \mu \mathrm{M} / \mathrm{g} \mathrm{FW}$, respectively, which indicates that PDS can recover the inhibitory effect of salt stress by raising the levels of SOD. On the other hand, the activity of ascorbate peroxidase (APX) was found similar in seedlings placed under control and PDS 2000 ppm treatments (Figure 6B). Upon salt treatment (150 and $200 \mathrm{mM})$, APX activity was lowered to 2.9 and $2.1 \mu \mathrm{M} / \mathrm{g}$ FW, respectively. Importantly, the addition of PDS $2000 \mathrm{ppm}$ to salt solutions (150 and $200 \mathrm{mM}$ ) increased the activity of APX to 3.7 and $4.1 \mu \mathrm{M} / \mathrm{g}$ FW (Figure 6B). This result indicates that under PDS 2000 ppm treatment, APX remains unaffected while it has the capability to alleviate the salt stress. The mechanism through which PDS alleviates APX needs further research. The activity of peroxidase (POD) under PDS $2000 \mathrm{ppm}$ was found to be approximately $0.08 \mu \mathrm{M} / \mathrm{g}$ FW while that of control was $0.05 \mu \mathrm{M} / \mathrm{g}$ FW (Figure 6C). Salinity stress at 150 and $200 \mathrm{mM}$ each reduced the POD activity to 0.04 and $0.03 \mu \mathrm{M} / \mathrm{g} \mathrm{FW}$, respectively. Interestingly, the POD activity was regained by the addition of PDS $2000 \mathrm{ppm}$ to salt 150 and $200 \mathrm{mM}$ solutions. The present data show that PDS $2000 \mathrm{ppm}$ increases the antioxidative enzymatic activity under salt stress. However, the fact that PDS alleviates salt stress and induces antioxidative activity is still worth answering.
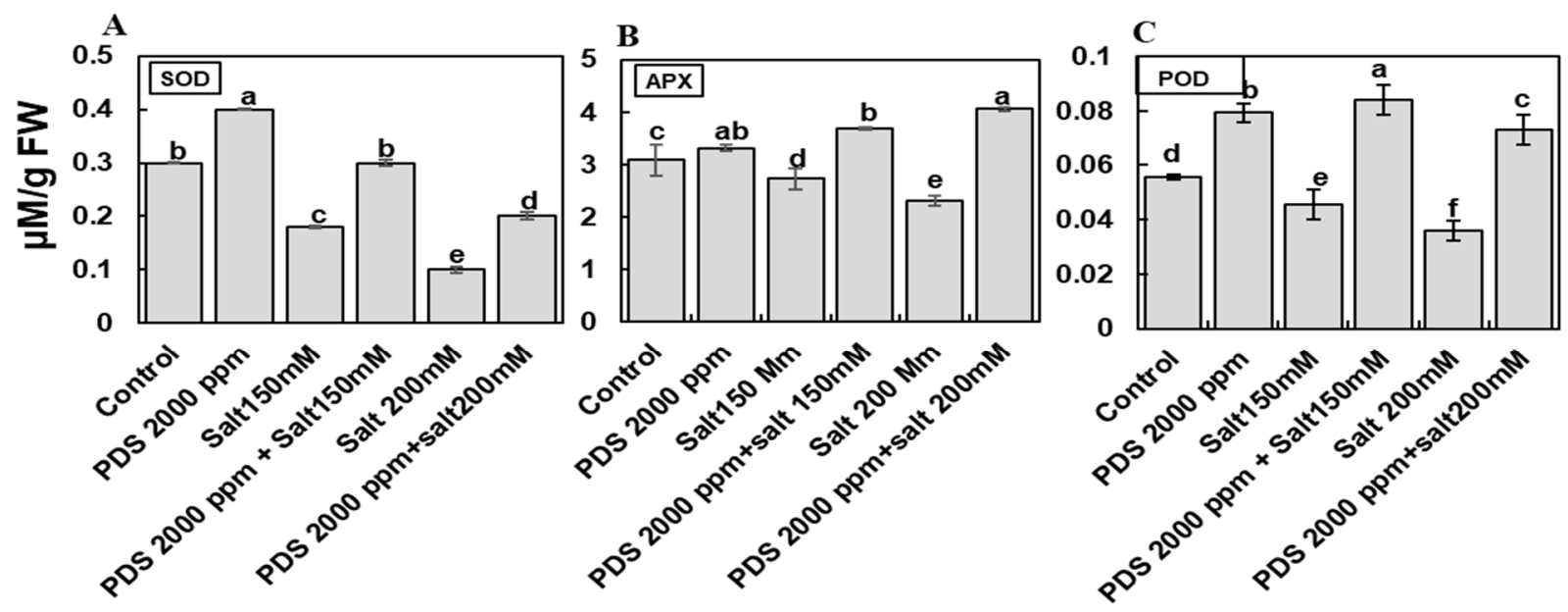

Treatments

Figure 6. Evaluation of antioxidant activity in PDS and salt-stress-treated wheat seedlings. SOD (A), APX (B) and POD (C). Wheat seeds were treated with PDS (2000 ppm), salinity (mimicked by 150 and $200 \mathrm{mM}$ ) and PDS + salt solution (PDS 2000 ppm + 150 or $200 \mathrm{mM}$ ). After seven days of germination, five randomly selected seedlings were collected from each treatment and enzymatic activity was measured. Enzymatic activity increased under PDS and PDS added to salt medium. However, the activities of POD, APX, and SOD were deceased under salt stress. All data were analyzed using one-way ANOVA, with multiple comparisons using the LSD test at a significance level of $p \leq 0.05$ $(n=5)$. The different lowercase alphabets represent homogeneous subsets and it's indicates the statistical significantly according to Fisher LSD at level $p<0.05$.

\section{Discussion}

Seed germination is the most important stage of development, which decides seedling establishment towards the success or failure of crop production. The germination process involves many physiological, biochemical, and molecular processes [34]. In the present 
study, we analyzed seed germination of wheat under different concentrations of PDS, including 2000, 1000, and 500 ppm. Our results showed that PDS 2000 ppm accelerated wheat germination rate and seedling growth including root, shoot length and fresh weight. Recent studies have reported enhanced seed germination rate and shoot/root length in maize and chickpea [34-37]. Accumulating evidence has shown PDS to be a seed germination promoter in many plant species, including Gyrostemon racemiger, Gyrostemon ramulosus, Anigozanthos flavidus, Zea mays, and Apium graveolens [17,37,38]. PDS has been determined to promote root growth in tomato and increase shoot length and fresh weight of okra, bean, tomato, Benyard and rice [6,39-41]. Butenolides, also known as Karrikins, are a class of chemicals that enhance seed germination and accelerate plant growth [27,42]. A recent study shows that butenolides promote seed germination by mediating the signaling transduction of several phytohormones including ABA, auxin, and gibberellin [43]. These previous results along with our results emphasize that PDS positively affects seed germination, seedling root/shoot length and fresh weight. Abiotic stresses, including salt stress, are critical factors affecting plant growth, particularly seed germination [44]. In wheat, we report reduced germination percentage under salt stress condition as shown in Figure 1A,B. Previous studies have shown that salt stress negatively affects overall seed germination in rice cultivars, tomato and Phaseolus species [6-10]. Our results reveal that upon application of PDS, seed germination was restored under salt stress (Figure 1A,B). A study has shown that in maize, smoke solution has well-proven alleviation effects on salt stress and has improved the seed germination rate $[24,28,45]$. Karrikins have been found to improve seed germination and seedling growth in Eragrostis tef (zucc.) under heat and osmotic stresses [26]. Studies have reported that Karrikins can promote seed germination by regulating expressions of GA biosynthesis-related genes, enhancing ROS-scavenging antioxidants and sugar mobilization in Arabidopsis, maize and beans [27,28]. All these findings along with our results suggest that smoke compounds play an important role in the regulation of physiological processes and in controlling excess salt in seeds during the germination process. Conversely, Karrikins negatively regulate Arabidopsis seed germination under different abiotic stress conditions [46]. These results indicate that smoke and smoke-isolated compounds play vast roles in plant growth during stress conditions.

Although much has been reported about the promoting effects of PDS on seed germination and seedling growth, how PDS enhances seed germination under salt stress has not been studied so far. The present study for the first time measured the expression patterns of germination marker genes. According to our findings, application of PDS alone and PDS + salt solution ( $150 \mathrm{mM}$ and $200 \mathrm{mM}$ ) enhanced the expression levels of TaSAM and TaBGU (germination positive effectors) compared to control (Figure 2A,B) [47,48]. Importantly, PDS significantly reduced the expression patterns of TaLEA and TaGASR34, which are the negative effectors of seed germination [48] (Figure 2E,F). High expression levels of germination positive marker genes including $B G U, M B P, M Y R$, and $P H Y B$ and low expression of SEEDSP and LEAP have been reported in Arabidopsis transgenic plants under salt and drought stress [49]. On the contrary, under salt and drought stress, Arabidopsis exhibits low levels of BGU, MBP, MYR, and high levels of SEEDSP and LEAP expression [50]. Collectively, these findings suggest that gemination marker genes play an important role in seed germination by modulating their expression levels. These results point towards the conclusion that PDS might play an important role in regulating seed germination-related signaling pathways. However, through which mechanism regulation takes place needs to be answered.

Salt stress causes reduction in seedling growth and fresh weight in different plant species. Our results show that salt stress reduces wheat root/shoot length and seedling biomass under salt stress. Plant-derived smoke solutions have well-proven alleviation effects on maize seedlings and fresh biomass under salt stress [24,28,45]. Karrikins have shown striking alleviating effects on seedling growth and seed germination under salt and osmotic stress [25]. These studies show that improvement in root/shoot length with the application of PDS in wheat seedlings might provide strength to the plantlets against salt 
stress in wheat. These results suggest that PDS could have the capability to alleviate salt stress in crop species.

Plants adopt certain intrinsic molecular mechanisms to withstand salt stress [49]. These include high expression levels of salt-responsive marker genes such as SOS1, SOS4, $H K T 2, P 3 C S$, and BADH. These salt stress marker genes have previously been found crucial for plant growth and in the regulation of signaling pathways in various plant species under salt stress [51-54]. In the past, reports have shown that the SOS family, including SOS1 proteins, plays a significant role in the regulation of salt stress in Arabidopsis [52,55]. Overexpression of $B A D H$ and HKT2 have secured plants from salt stress [51,53]. Lately, application of Karrikin has reported induction of SOS1, WKKY33, DREB2 and EFR5 genes under salt stress in Sapium sabiforum [25]. In the present study, PDS significantly enhanced the expression levels of SOS4, HKT2, P3CS and BADH under salt stress (Figure 4B-E), which agreed with a previous study that Karrikins could upregulate the expressions of salt stress marker genes under salt stress [51], and suggested that the PDS-responsive genes might have direct interactions with the stress regulatory genes in wheat. How the expressions of salt-related genes have been modulated by PDS is worth answering.

Reportedly, abiotic stresses accumulate ROS in the cell, which can cause cellular oxidative stress and could damage the cell [56]. In animals and plants, over accumulation of ROS and lipid peroxidation along with $\mathrm{H}_{2} \mathrm{O}_{2}$ are considered as an important marker of cell damage [57]. In our study, $\mathrm{H}_{2} \mathrm{O}_{2}$ and lipid peroxidase contents were significantly lower in wheat seedlings treated with 2000 ppm PDS under salt stress (Figure $5 \mathrm{~A}-\mathrm{C}$ ). Our results in line with previous results suggest that PDS plays a significant role in ROS scavenging in wheat under salt stress conditions.

Accumulating evidence has increasingly shown that stress-tolerant plants produce high amounts of antioxidant enzymes such as APX, POD, and SOD to eliminate excess ROS in the cell. SOD has been reported to detoxify $\mathrm{H}_{2} \mathrm{O}_{2}$ by enhancing the levels of APX, POD and CAT [58-62]. PDS 2000 ppm increased the levels of antioxidant enzymes, i.e., POD, SOD, and APX, under salt stress (Figure 6A-C), which may partly explain why PDS-treated wheat plantlets were more resistant to salt stress. Overall, maintenance of redox homeostasis and prevention of oxidative damage during salt stress acclimation emphasizes the significance of PDS in restoring cellular activities by increasing antioxidants and decreasing $\mathrm{H}_{2} \mathrm{O}_{2}$ and lipid peroxidation.

\section{Materials and Methods}

\subsection{Preparation of PDS and Salt Solutions}

To prepare the aqueous PDS solution, aerial parts, which mainly consist of leaves of Cymbopogon jwarncusa L. (C. jwarncusa) were collected from the surroundings of Kohat University of Science and Technology, Pakistan. The collected plant parts were thoroughly washed with distilled water to remove the dust particles. Cleaned plants were shade dried for 12-15 days. The C. jwarncusa-derived smoke solution was prepared following the method described earlier [63]. The semi dried plant weighing $333 \mathrm{~g}$ was smoldered on a heater until the whole plant portion was converted to ash. The smoke was bubbled through $1 \mathrm{~L}$ of distilled water in a beaker. The resultant solution was a concentrated PDS stock solution, which was filtered and stored at $4{ }^{\circ} \mathrm{C}$ for further use. Salt $(\mathrm{NaCl})$ solutions of 150 and $200 \mathrm{mM}$ were prepared for salt stress treatment. PDS stock solution was further diluted to 500, 1000 and 2000 ppm for subsequent use. Distilled water was used for control treatment (schematic representation Figure 7).

\subsection{Plant Material and Treatment with Plant-Derived Smoke Solution and Salt Stress}

Wheat seeds (Triticum aestivum L. cv Pasheena 2017) were collected from the Cereal Crop Research Institute (CCRI), District, Nowshera. The seeds were thoroughly washed and sterilized with $0.1 \%$ sodium hypochloride $(\mathrm{NaOCl})$ for one minute and then washed with 70\% ethanol solution for three minutes followed by three times washing with sterilized water each for one minute. Seed germination test was conducted three times before giving 
different treatments to seeds. The germination test resulted in $100 \%$ germination in all replicants which confirmed that wheat seeds were healthy and viable. Later, uniform sized seeds were selected and allowed to germinate on Petri plates $(150 \mathrm{~mm} \times 60 \mathrm{~mm} \times 100 \mathrm{~mm})$ containing double layered Whatman No.1 filter paper. Petri plates and filter paper were pre-sterilized before the experiment. Twelve seeds were sown on each Petri plate and three Petri dishes were used for each treatment. For PDS treatment, seeds were treated with PDS at 2000 ppm, 1000 ppm and 500 ppm. For salt stress, two treatments at two different concentrations were used, 150 and $200 \mathrm{mM}$. For alleviation experiments, salt solution supplemented with PDS was used. Seeds treated with distilled water were considered as control. All Petri plates were kept at $25^{\circ} \mathrm{C}, 16 \mathrm{~h}$ light and $7 \mathrm{~h}$ dark at $60 \%$ humidity. Measurement of germination rate started after $24 \mathrm{~h}$. Seeds with protruded radical were considered as germinated. The morphological parameters, including root, shoot length, and seedling fresh weight, were recorded at day 7 of germination when clear differences between control and treated seedings were visible. All independent experiments were replicated three times.

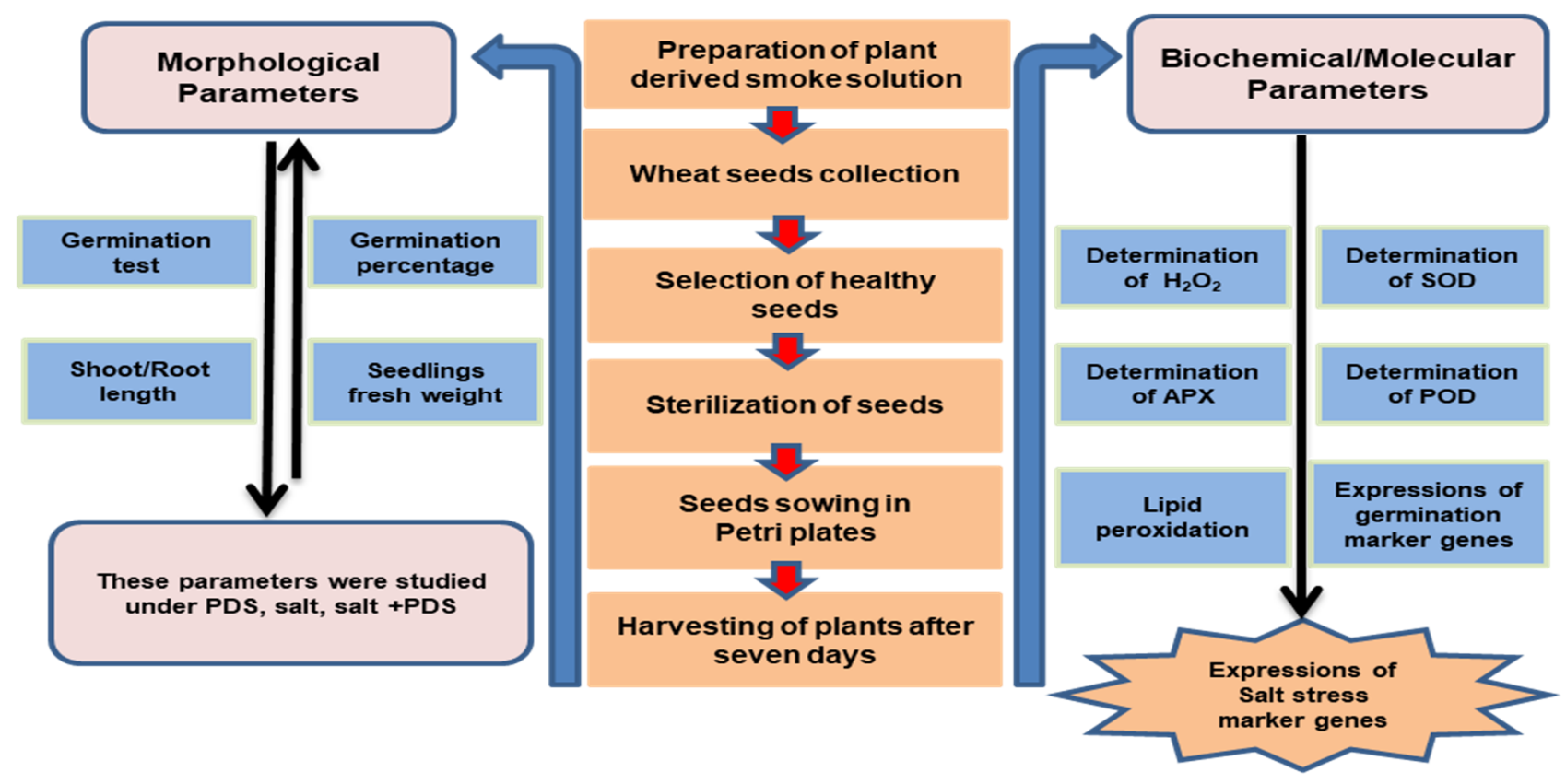

Figure 7. The effects of PDS on wheat growth were studied using an experimental design. Wheat seeds were treated with 500, 1000 and 2000 ppm PDS followed by selection of 2000 ppm for alleviation experiment based on best promoting effects. Wheat seeds were given salt stress (150-200 mM), which caused inhibition of seed germination and seedling growth. Supplementation of PDS at $2000 \mathrm{ppm}$ concentration alleviated the salt stress. Figure 6 is schematic representation of stepwise experimental layout of morphological, physiological, and molecular parameters.

\subsection{Total RNA Extraction and Analysis of $q R T-P C R$}

Using Ensemble Plants (http:/ / plants.ensembl.org, accessed on 15 September 2021) and NCBI (https://www.ncbi.nlm.nih.gov, accessed on 15 September 2021), full CDs sequences of wheat genes were extracted and identified by local blast using Arabidopsis amino acid sequences as a reference in blast-2.2.31. The qRT-PCR (quantitative real time Polymerase chain reaction) primers were designed using Gene Runner software. Ta_Actin and Ta_Tubulin were used as internal housekeeping genes. To determine whether salt stress was properly given to wheat, first, the expression level of DREB2 was analyzed. To analyze expressions of germination-responsive genes, germinated seed samples were collected after $48 \mathrm{~h}$ of germination, emersed in liquid nitrogen and stored in $-80^{\circ} \mathrm{C}$ refrigerator. To extract total RNA, plant samples were ground using liquid nitrogen and $100 \mathrm{mg}$ of the ground sample was used. Using RNeasy plant mini kit from Qiagen (Valencia, CA, USA), 
RNA extraction and purification was performed. The quantification of RNA in each sample was performed by Rotor-Gene thermal cycler (Q PCRr, Qiagen) and SYBR Green RT-PCR kit (Qiagen) as previously described [64,65]. Gene-specific primers, housekeeping genes and primers for salt stress marker genes are shown in Supplementary Tables S1 and S2.

\subsection{Measurement of $\mathrm{H}_{2} \mathrm{O}_{2}$ and Lipid Peroxidation}

To determine the level of $\mathrm{H}_{2} \mathrm{O}_{2}$ PDS, salt stress and PDS + salt stress, the procedure used earlier was followed [66]. At a wavelength of $390 \mathrm{~nm}$, a reaction combination of $1 \mathrm{~mL}$ enzyme extract, $1 \mathrm{~mL} 10 \mathrm{mM}$ potassium phosphate buffer ( $\mathrm{pH} 7.0)$, and $2 \mathrm{~mL} 1 \mathrm{M}$ potassium iodide (KI) was analyzed spectrophotometrically. It was measured in milligrams per gramme of fresh weight (mg/g FW). Next, the level of lipid peroxidation was measured in terms of thiobarbituric acid reactive substances (TBARS) under PDS, salt and PDS supplemented salt medium. At day 7,0.2 g of fresh seedlings were collected and grounded in mortar with help of pestle using $3 \mathrm{~mL}$ of $25 \%$ (TBA) thiobarbituric acid and $10 \%$ TCA (trichloroacetic acid) [67]. The homogenate was centrifuged for $10 \mathrm{~min}$ at $10,000 \times \mathrm{g}$ after being heated for $30 \mathrm{~min}$ at $95{ }^{\circ} \mathrm{C}$ and then rapidly cooled in an ice bath. At $532 \mathrm{~nm}$, the absorbance was measured, and non-specific turbidity was adjusted at $600 \mathrm{~nm}$.

\subsection{Quantification of Antioxidant Enzymes}

To measure antioxidant enzyme activity, seedlings were harvested at day 7 after germination and a $500 \mathrm{mg}$ sample of fresh seedlings was taken and placed in a prechilled pestle and mortar to measure enzymatic antioxidants. The material was then crushed in a $\mathrm{K}_{2} \mathrm{HPO}_{4} .2 \mathrm{H}_{2} \mathrm{O}$ (potassium phosphate) buffer ( $\left.\mathrm{pH} 7.8\right)(10 \mathrm{~mL}$ out of $50 \mathrm{mM}$ ). After cooling the samples, they were centrifuged at $4{ }^{\circ} \mathrm{C}$ for $20 \mathrm{~min}$ at $12,000 \mathrm{rpm}$. After centrifugation, the supernatant was collected for further enzymatic analysis. The homogenate was centrifuged for $10 \mathrm{~min}$ at $10,000 \times g$ after being heated for $30 \mathrm{~min}$ at $95^{\circ} \mathrm{C}$ and then rapidly cooled in an ice bath.

\subsection{Measurement of Superoxide Dismutase (SOD) Activity}

To determine the SOD, $250 \mathrm{~mL}$ of the total reactive homogenous mixture was used (Nitroblue tetrazoilum chloride $15.5 \mathrm{mg}$, methionine $485 \mathrm{mg}$, EDTA $10 \mathrm{mg}$, and Riboflavin $0.02 \mathrm{mg}$ ). To avoid degradation, the reaction substrate was kept in the refrigerator after being prepared and wrapped with aluminum foil. SOD was measured using a $2.725 \mathrm{~mL}$ homogeneous mixture, $25 \mu \mathrm{L}$ enzyme extract, and $25 \mu \mathrm{L} \mathrm{H}_{2} \mathrm{O}_{2}$, as well as a blank sample (without enzyme extract) exposed to light (4000 lux for $20 \mathrm{~min}$ ).

For control samples distilled water $(25 \mu \mathrm{L})$ was used instead of enzyme extract. For a stable reaction, when the mixture was exposed to lux, the tubes were wrapped in a black cloth. The samples were quantified at $560 \mathrm{~nm}$ using glass cuvettes [68].

\subsection{Quantification of Guaiacol Peroxidase (POD) and Ascorbate Peroxidase (APX) Activity}

The activities of POD and APX were measured using the techniques described earlier [51]. The reaction sample included enzyme extract, $1.5 \%$ guaiacol and $\mathrm{H}_{2} \mathrm{O}_{2}$ each $100 \mu \mathrm{L}$ quantity. Control sample contained PBS $(2.8 \mathrm{~mL})$, guaiacol $(0.1 \mathrm{~mL})$ and $\mathrm{H}_{2} \mathrm{O}_{2}$ $(0.1 \mathrm{~mL})$. Using spectrophotometer with absorbance wavelength $470 \mathrm{~nm}$ the POD activity was measured. The buffer composition consisted of potassium phosphate, EDTA-Na ${ }_{2}$, $\mathrm{H}_{2} \mathrm{O}_{2}$, ascorbic acid, and enzymes extract. The wavelength used was $290 \mathrm{~nm}$.

\subsection{Statistical Analysis}

Three repetitions of each experiment were examined. The data were analyzed with the help of the statistics 9 software (Analytical Software 2105 Miller Landing Rd Tallahassee, FL 32312, version 8.1 days, Tallahassee, FL, USA), and all of the results were presented as mean standard deviation (SD). One-way analysis of variance (ANOVA) was used to determine the significance of differences between the control and treatment groups, with the least significant variance at $(p \leq 0.05)$. For multiple comparison, LSD test was performed. 


\section{Conclusions}

The present study proves that application of PDS significantly improved seed germination and the seedling growth of wheat under salt stress. Particularly, it induced the expressions of many germination marker genes and salt-stress-related genes. Supplementation of PDS significantly enhanced the activities of the antioxidants such as POD, APX, and SOD, which resulted in a significant reduction of $\operatorname{ROS}\left(\mathrm{H}_{2} \mathrm{O}_{2}\right)$, and lipid peroxidation under salt stress. Conclusively, our study suggests that PDS can improve seed germination and seedling growth under salt stress via regulating redox homeostasis as well as by modulating expressions of stress regulatory genes (Figures 1 and 3). The present study clarifies that PDS has stress modulation capability at the physiological and molecular level, which will lay a foundation for further understanding of the role of PDS in the regulation of other abiotic stress tolerance in plants. This study also provides a novel clue for farmers and nursery growers in saline soil on how to promote the crop seedling's growth under stressed conditions. It would be even more beneficial to analyze the effect of PDS on flowering and yield of wheat and other crops. Further, to understand the functions of PDS in plant growth and stress responses, functional characterization of PDS-responsive genes and downstream signaling pathways are necessary to be investigated by studying mutant lines.

Supplementary Materials: The following are available online at https: / www.mdpi.com/article / 10.3390 /agronomy12010028/s1, Table S1. Gene specific primer pairs of germination-responsive genes and salt stress marker genes used in quantitate real-time RT-PCR analysis; Table S2. Sequences of the germination marker genes, salt stress marker genes are listed below; Figure S1. (A) Effect of PDS 4000 and 6000 ppm on seed germination rate of wheat. (B) Levels of Actin and Tubulin under PDS, salt and PDS+salt medium. (C) Images of seed germination and seedling growth of wheat. List of Abbreviations.

Author Contributions: Conceptualization, G.N., S.H.B. and S.S.; Data curation, A.K. and N.A. (Neelam Afroz); Formal analysis, N.H., N.A. (Neelam Afroz), K.I., S.S., A.B., H.H. and G.N.; Funding acquisition, R.U., E.A.A. and A.B.; Investigation, N.H., N.A. (Neelam Afroz), K.I., S.H.B., N.T., N.A. (Nisar Ahmad) and G.N.; Methodology, N.H., N.A. (Nisar Ahmad), K.I., A.K., S.H.B., N.T. and G.N.; Project administration, S.R.; Resources, N.A. (Nisar Ahmad), R.U., E.A.A., A.B. and H.H.; Software, E.A.A.; Supervision, G.N. and S.R.; Validation, S.R., A.K., A.B. and H.H.; Visualization, S.S.; Writing-original draft, G.N., R.U. and A.B. All authors have read and agreed to the published version of the manuscript.

Funding: This research was funded by the Researchers Supporting Project No. RSP-2021/45, King Saud University, Riyadh, Saudi Arabia.

Institutional Review Board Statement: Not applicable.

Informed Consent Statement: Not applicable.

Data Availability Statement: All related data are within the manuscript.

Acknowledgments: The authors wish to thank Researchers Supporting Project No. (RSP-2021/45) at King Saud University, Riyadh, Saudi Arabia for financial support.

Conflicts of Interest: The authors declare no conflict of interest.

\section{References}

1. Ganie, S.A.; Reddy, A.S. Stress-Induced Changes in Alternative Splicing Landscape in Rice: Functional Significance of Splice Isoforms in Stress Tolerance. Biology 2021, 10, 309. [CrossRef]

2. Foley, J.A.; Ramankutty, N.; Brauman, K.A.; Cassidy, E.S.; Gerber, J.S.; Johnston, M.; Mueller, N.D.; O'Connell, C.; Ray, D.K.; West, P.C.; et al. Solutions for a cultivated planet. Nature 2011, 478, 337-342. [CrossRef] [PubMed]

3. Munns, R.; Mark, T. Mechanisms of salinity tolerance. Annu. Rev. Plant Biol. 2008, 59, 651-681. [CrossRef]

4. Chen, J.; Xu, W.; Velten, J.; Xin, Z.; Stout, J. Characterization of maize inbred lines for drought and heat tolerance. J. Soil Water Conser. 2012, 67, 354-364. [CrossRef]

5. Akram, M.S.; Shahid, M.; Tariq, M.; Azeem, M.; Javed, M.T.; Saleem, S.; Riaz, S. Deciphering Staphylococcus sciuri SAT-17 mediated anti-oxidative defense mechanisms and growth modulations in salt stressed maize (Zea mays L.). Front. Microbiol. 2016, 7, 867. [CrossRef] [PubMed] 
6. Zeng, L.; Shannon, M.C. Salinity effects on seedling growth and yield components of rice. Crop Sci. 2000, 40, 996-1003. [CrossRef]

7. Bayuelo-Jimenez, J.S.; Craig, R.; Lynch, J.P. Salinity tolerance of Phaseolus species during germination and early seedling growth. Crop Sci. 2002, 42, 1584-1594. [CrossRef]

8. Alam, M.Z.; Stuchbury, T.; Naylor, R.E.; Rashid, M.A. Effect of salinity on growth of some modern rice cultivars. J. Agron. 2004, 3, 223-236. [CrossRef]

9. Omami, E.N. Effects of salinity stress on amaranth seed germination and seedling growth. N. Z. J. Crop Horticul. Sci. 2005, 34, 35-59.

10. Jain, N.; Kulkarni, M.G.; Van Staden, J. A butenolide, isolated from smoke, can overcome the detrimental effects of extreme temperatures during tomato seed germination. Plant Growth Regul. 2006, 49, 263-267. [CrossRef]

11. Gill, S.S.; Tuteja, N. Reactive oxygen species and antioxidant machinery in abiotic stress tolerance in crop plants. Plant Physiol. Bioch. 2010, 48, 909-930. [CrossRef] [PubMed]

12. Ganie, S.A.; Molla, K.A.; Henry, R.J.; Bhat, K.V.; Mondal, T.K. Advances in understanding salt tolerance in rice. Theor. Appl. Genet. 2019, 132, 851-870. [CrossRef]

13. Ganie, S.A.; Mazumder, A.; Kiran, K.; Hossain, F.; Sharma, R.; Mondal, T.K. Transcriptional dynamics of Zn-accumulation in developing kernels of maize reveals important Zn-uptake mechanisms. Genomics 2020, 112, 3435-3447. [CrossRef] [PubMed]

14. Xie, T.; Gu, W.; Meng, Y.; Li, J.; Li, L.; Wang, Y.; Qu, D.; Wei, S. Exogenous DCPTA ameliorates simulated drought conditions by improving the growth and photosynthetic capacity of maize seedlings. Nature 2017, 7, 12684. [CrossRef]

15. Zhang, H.; Li, Y.; Zhu, J.K. Developing naturally stress-resistant crops for a sustainable agriculture. Nat. Plants 2018, 4, 989-996. [CrossRef] [PubMed]

16. Kamran, M.; Khan, A.L.; Ali, L.; Hussain, J.; Waqas, M.; Al-Harrasi, A.; Imran, Q.M.; Kim, Y.H.; Kang, S.M.; Yun, B.W.; et al. Hydroquinone; a novel bioactive compound from plant-derived smoke can cue seed germination of lettuce. Front. Chem. 2017, 5, 30. [CrossRef] [PubMed]

17. Thomas, T.H.; van Staden, J. Dormancy break of celery (Apium graveolens L.) seeds by plant-derived smoke extract. Plant Growth Regul. 1995, 17, 195-198. [CrossRef]

18. Doherty, L.C.; Cohn, M.A. Seed dormancy in red rice (Oryza sativa). XI. Commercial liquid smoke elicits germination. Seed Sci. Res. 2000, 10, 415-421. [CrossRef]

19. Sparg, S.G.; Kulkarni, M.G.; van Staden, J. Aerosol smoke and smoke water stimulation of seedling vigor of a commercial maize cultivar. Crop Sci. 2006, 46, 1336-1340. [CrossRef]

20. Aremu, A.O.; Bairu, J.F.X.; Finnie, V.; van Staden, J. Stimulatory role of smoke water and karrikinolide on the photosynthetic pigment and phenolic contents of micropropagated 'Williams' bananas. Plant Growth Regul. 2012, 67, 271-279. [CrossRef]

21. Kulkarni, M.G.; Amoo, S.O.; Kandari, L.S.; van Staden, J. Seed germination and phytochemical evaluation in seedlings of Aloe arborescens Mill. Plant Biosyst. 2013, 148, 460-466. [CrossRef]

22. Waheed, M.A.; Jamil, M.; Daud, M.; Shakir, S.; Rehman, S. Effect of plant-derived smoke solutions onphysiological and biochemical attributes of maize (Zea mays L.) under salt stress. Pak. J. Bot. 2016, 48, 1763-1774.

23. Khatoon, A.; Rehman, S.U.; Aslam, M.M.; Jamil, M.; Komatsu, S. Plant-Derived Smoke Affects Biochemical Mechanism on Plant Growth and Seed Germination. Int. J. Mol. Sci. 2020, 21, 7760. [CrossRef]

24. Jamil, M.; Kanwal, M.; Aslam, M.M.; Shakir, S.K.; Malook, I.; Tu, J.; Rehman, S. Effect of plant-derived smoke priming on physiological and biochemical characteristics of rice under salt stress condition. Aust. J. Crop. Sci. 2014, 8, $159-170$.

25. Shah, F.A.; Wei, X.; Wang, Q.; Liu, W.; Wang, D.; Yao, Y.; Hu, H.; Chen, X.; Huang, S.; Hou, J.; et al. Karrikin Improves Osmotic and Salt Stress Tolerance via the Regulation of the Redox Homeostasis in the Oil Plant Sapium sebiferum. Front. Plant Sci. 2020, 11, 216. [CrossRef]

26. Ghebrehiwot, H.M.; Kulkarni, M.G.; Kirkman, K.P.; Staden, J.V. Smoke-water and a smoke-isolated butenolide improve germination and seedling vigour of Eragrostis tef (zucc.) trotter under high temperature and low osmotic potential. J. Agron. Crop Sci. 2008, 194, 270-277. [CrossRef]

27. Nelson, D.C.; Scaffidi, A.; Dun, E.A.; Waters, M.T.; Flematti, G.R.; Dixon, K.W.; Beveridge, C.A.; Ghisalbert, E.L.; Smith, S.M. F-box protein MAX2 has dual roles in karrikin and strigolactone signaling in Arabidopsis thaliana. Proc. Natl. Acad. Sci. USA 2011, 108, 8897-8902. [CrossRef]

28. Sunmonu, T.O.; Kulkarni, M.G.; Staden, J.V. Smoke-water, karrikinolide and gibberellic acid stimulate growth in bean and maize seedlings by efficient starch mobilization and suppression of oxidative stress. S. Afr. J. Bot. 2016, 102, 4-11. [CrossRef]

29. Shabir, S.; Ilyas, N.; Asif, S.; Iqbal, M.; Kanwal, S.; Ali, Z. Deciphering the role of plantoderived smoke solution in ameliorating saline stress and improving physiological, biochemical and growth responses of wheat. J. Plant Growth Regul. $2021,10,1007$.

30. Liu, T.; Hou, G.G.; Cardin, M.; Marquart, L.; Dubat, A. Quality attributes of whole-wheat flour tortillas with sprouted whole-wheat four substitution. LWT 2017, 77, 1-7. [CrossRef]

31. Smol, J.P. Climate change: A planet in fux. Nature 2012, 483, 12-15. [CrossRef] [PubMed]

32. Sun, Z.W.; Ren, L.K.; Fan, J.W.; Li, Q.; Wang, K.J.; Guo, M.M.; Chen, F. Salt response of photosynthetic electron transport system in wheat cultivars with contrasting tolerance. Plant Soil Environ. 2016, 62, 515-521.

33. Shi, H.; Ishitani, M.; Kim, C.; Zhu, J.K. The Arabidopsis thaliana salt tolerance gene SOS1 encodes a putative $\mathrm{Na}^{+} / \mathrm{H}^{+}$antiporter. Proc. Natl. Acad. Sci. USA 2000, 97, 6896-6901. [CrossRef]

34. Aslam, M.M.; Jamil, M.; Khatoon, A.; Hendawy, S.E.; Suhaibani, N.A.; Malook, I.; Rehman, S. Physiological and biochemical responses of maize (Zea mays L.) to plant derived smoke solution. Pak. J. Bot. 2017, 49, 435-443.

35. Aslam, M.M.; Rehman, S.; Khatoon, A.; Jamil, M.; Yamaguchi, H.; Hitachi, K.; Komatsu, S. Molecular responses of maize shoot to a plant derived smoke solution. Int. J. Mol. Sci. 2019, 20, 1319. [CrossRef] 
36. Rehman, A.; Rehman, S.U.; Khatoon, A.; Qasim, M.; Itoh, T.; Iwasaki, Y.; Wang, X.; Sunohara, Y.; Matsumoto, H.; Komatsu, S. Proteomic analysis of the promotive effect of plant-derived smoke on plant growth of chickpea. J. Proteom. 2018, 176, 56-70. [CrossRef]

37. Nazish, M.; Zafar, M.; Ahmad, M.; Sultana, S.; Ullah, R.; Alqahtani, A.S.; Ullah, F.; Ahmad, S.; Ashfaq, S.; Ullah, F. Palynomorphological investigations of halophytic taxa of Amaranthaceae through SEM from Salt range of Northern Punjab, Pakistan. Microsc. Res. Tech. 2019, 82, 304-316. [CrossRef] [PubMed]

38. Downes, K.S.; Light, M.E.; Posta, M.; Kohout, L.; van Staden, J. Comparison of germination responses of Anigozanthos flavidus (Haemodoraceae), Gyrostemon racemiger and Gyrostemon ramulosus (Gyrostemonaceae) to smoke-water and the smoke-derived compounds karrikinolide (KAR1) and glyceronitrile. Ann. Bot. 2013, 111, 489-497. [CrossRef] [PubMed]

39. Taylor, J.L.S.; van Staden, J. Plant-derived smoke solutions stimulate the growth of Lycopersicon esculentum roots in vitro. Plant Growth Regul. 1998, 26, 77-83. [CrossRef]

40. Van Staden, J.; Sparg, S.G.; Kulkarni, M.G.; Light, M.E. Post germination effects of the smoke-derived compound 3-methyl-2H-furo [2,3-c] pyran-2-one, and its potential as a preconditioning agent. Field Crop Res. 2006, 98, 98-105. [CrossRef]

41. Gorni, P.H.; de Lima, G.R.; de Oliveira Pereira, L.M.; Spera, K.D.; de Marcos Lapaz, A.; Pacheco, A. Increasing plant performance, fruit production and nutritional value of tomato through foliar applied rutin. Sci. Hortic. 2021, 294, 110755. [CrossRef]

42. Papenfus, H.B.; Kulkarni, G.; Stirk, W.A.; Rengasamy, K.R.R.; Salomon, M.V.; Piccoli, P.; Bottini, R.; van Staden, J. Interactions between a plant growth-promoting rhizobacterium and smoke-derived compounds and their effect on okra growth. J. Plant Nutr. Soil Sci. 2015, 178, 741-747. [CrossRef]

43. Meng, Y.; Shuai, H.; Luo, X.; Chen, F.; Zhou, W.; Yang, W.; Shu, K. Karrikins: Regulators involved in phytohormone signaling networks during seed germination and seedling development. Front. Plant Sci. 2017, 7, 2021. [CrossRef] [PubMed]

44. Dehnavi, A.R.; Zahedi, M.; Ludwiczak, A.; Perez, S.C.; Piernik, A. Effect of Salinity on Seed Germination and Seedling Development of Sorghum (Sorghum bicolor (L.) Moench) Genotypes. Agronomy 2020, 10, 859. [CrossRef]

45. Iqbal, M.; Raza, A.; Zulfiqar, S.; Athar, H.R.; Zafar, Z.U. Physiological quality improvement of salt imbibed maize (Zea mays L.) seeds by priming with smoke water. Agrochimical 2013, 56, 247-255.

46. Wang, M.; Xia, G. The landscape of molecular mechanisms for salt tolerance in wheat. Crop J. 2018, 6, 42-47. [CrossRef]

47. Yamaguchi, S.; Smith, M.W.; Brown, R.G.; Kamiya, Y.; Sun, T. Phytochrome regulation and differential expression of gibberellin 3 $\beta$-hydroxylase genes in germinating Arabidopsis seeds. Plant Cell. 1998, 10, 2115-2126. [CrossRef]

48. Gallardo, K.; Job, C.; Groot, S.P.; Puype, M.; Demol, H.; Vandekerckhove, J.; Job, D. Proteomic analysis of Arabidopsis seed germination and priming. Plant Physiol. 2001, 126, 835-848. [CrossRef] [PubMed]

49. Nawaz, G.; Lee, K.; Park, S.J.; Kim, Y.; Kang, H. A chloroplast-targeted cabbage DEAD-box RNA helicase BrRH22 confers abiotic stress tolerance to transgenic Arabidopsis plants by affecting translation of chloroplast transcripts. Plant Physiol. Biochem. 2018, 127, 336-342. [CrossRef] [PubMed]

50. Nawaz, G.; Sai, T.Z.T.; Lee, K.; Kim, Y.; Kang, H. Rice DEAD-box RNA helicase OsRH53 has negative impact on Arabidopsis response to abiotic stresses. J. Plant Growth Regul. 2018, 85, 153-163. [CrossRef]

51. Ni, J.; Wang, Q.; Shah, F.A.; Liu, W.; Wang, D.; Huang, S.; Fu, S.; Wu, L. Exogenous melatonin confers cadmium tolerance by counterbalancing the hydrogen peroxide homeostasis in wheat seedlings. Molecules 2018, 23, 799. [CrossRef]

52. Mahajan, S.; Pandey, G.K.; Tuteja, N. Calcium-and salt-stress signaling in plants: Shedding light on SOS pathway. Arch. Biochem. Biophys. 2008, 471, 146-158. [CrossRef]

53. Yinglu, S.; Liu, X.; Fu, L.; Qin, P.; Li, T.; Ma, X.; Wang, X. Overexpression of TaBADH increases salt tolerance in Arabidopsis. Can. J. Plant Sci. 2019, 99, 546-555.

54. Shi, H.; Zhu, J.K. SOS4, A Pyridoxal Kinase Gene, Is Required for Root Hair Development in Arabidopsis1. Plant Physiol. 2002, 129, 585-593. [CrossRef]

55. Zhu, J.K.; Liu, J. An Arabidopsis mutant that requires increased calcium for potassium nutrition and salt tolerance. Proc. Natl. Acad. Sci. USA 1997, 94, 14960-14964.

56. Ayala, A.; Munoz, M.F.; Arguelles, S. Lipid peroxidation: Production, metabolism, and signaling mechanisms of malondialdehyde and 4-hydroxy-2-nonenal. Oxidat. Med. Cell. Longev. 2014, 2014, 360438. [CrossRef] [PubMed]

57. Nita, M.; Grzybowski, A. The role of the reactive oxygen species and oxidative stress in the pathomechanism of the age-related ocular diseases and other pathologies of the anterior and posterior eye segments in adults. Oxidat. Med. Cell. Longev. 2016, 2016, 3164734. [CrossRef] [PubMed]

58. Asada, K. The water-water cycle as alternative photon and electron sinks. Philos. Trans. R. Soc. Lond. 2000, 355, 1419-1431. [CrossRef] [PubMed]

59. Cavalcanti, F.R.; Lima, J.P.; Ferreira-Silva, S.L.; Viegas, R.A.; Silveira, J.A. Roots and leaves display contrasting oxidative response during salt stress and recovery in cowpea. Plant Physiol. 2007, 164, 591-600. [CrossRef]

60. Mullineaux, P.M.; Karpinski, S.; Jiménez, A.; Cleary, S.P.; Robinson, C.; Creissen, G.P. Identification of cDNAS encoding plastid-targeted glutathione peroxidase. Plant J. 2010, 13, 375-379. [CrossRef]

61. Chen, S.; Heuer, B. Effect of genotype and exogenous application of glycinebetaine on antioxidant enzyme activity in native gels of 7-day-old saltstressed tomato (Solanum lycopersicum) seedlings. Sci. Horticult. 2013, 162, 106-116. [CrossRef]

62. Del Río, L.A.; Corpas, F.J.; López-Huertas, E.; Palma, J.M. Plant superoxide dismutases: Function under abiotic stress conditions. In Antioxidants and Antioxidant Enzymes in Higher Plants; Gupta, D.K., Palma, J.M., Corpas, F.J., Eds.; Springer: Cham, Switzerland, 2018; pp. 1-26. 
63. Tieu, A.; Dixon, K.W.; Sivasithamparam, K.; Plummer, J.A.; Sieler, I.M. Germination of four species of native western Australian plant using plant-derived smoke. Aust. J. Bot. 1999, 47, 207-219. [CrossRef]

64. Kim, J.S.; Park, S.J.; Kwak, K.J.; Kim, Y.O.; Kim, J.Y.; Song, J.; Jang, B.; Jung, C.H.; Kang, H. Cold shock domain proteins and glycine-rich RNA-binding protein from Arabidopsis thaliana can promote the cold adaptation process in Escherichia coli. Nucleic Acids Res. 2007, 35, 506-516. [CrossRef]

65. Kim, J.; Le, T.N.N.; Kang, H. Artificial targeting of a nucleus-encoded RNA-binding protein AtRZ1a to chloroplasts affects flowering and ABA response of Arabidopsis thaliana. J. Plant Biol. 2017, 60, 278-284. [CrossRef]

66. Willekens, H.; Chamnongpol, S.; Davey, M.; Schraudner, M.; Langebartels, C.; Van Montagu, M.; Van Camp, W. Catalase is a sink for $\mathrm{H}_{2} \mathrm{O}_{2}$ and is indispensable for stress defence in C3 plants. EMBO J. 1997, 16, 4806-4816. [CrossRef] [PubMed]

67. Hodges, D.M.; DeLong, J.M.; Forney, C.F.; Prange, R.K. Improving the thiobarbituric acid-reactive-substances assay for estimating lipid peroxidation in plant tissues containing anthocyanin and other interfering compounds. Planta 1999, 207, 604-611. [CrossRef]

68. Beauchamp, C.; Fridovich, I. Superoxide dismutase: Improved assays and an assay applicable to acrylamide gels. Anal. Biochem. 1971, 44, 276-287. [CrossRef] 